\title{
Trade-offs versus reassurance: framing competing risks in the 2016 Zika outbreak
}

\author{
Lejla Dervisevic $^{1} \cdot$ Leigh Raymond $^{1}$ (D) . Linda J. Pfeiffer ${ }^{1} \cdot$ Jessica V. Merzdorf ${ }^{1}$
}

Accepted: 20 August 2021 / Published online: 6 September 2021

(c) The Author(s), under exclusive licence to Springer Science+Business Media, LLC, part of Springer Nature 2021

\begin{abstract}
Environmental threats increasingly entail important risks from government responses. In considering the risks of a new vector-borne disease, for example, decision-makers must also grapple with potential risks from responses such as the aerial spraying of pesticides. In communicating about these complex risks, public officials often choose different "frames" that promote different conceptualizations of the issue. Yet prior research has paid limited attention to how public officials frame the related risks of the environmental threat and the public response. This paper starts to fill that gap by conducting a content analysis of statements by public officials regarding risks from the threat of a local outbreak of the Zika virus in South Florida in 2016, as well as risks from the response of aerial pesticide spraying. Based on limited prior research, we hypothesize that public officials are likely to have adopted a "risk maximization" frame that stressed the high risks from exposure to Zika, but a "risk trade-off" frame when discussing aerial spraying. In actuality, we find that officials strongly favored a "reassurance" frame that downplayed both types of risks. Based on this analysis, we suggest framing strategies for disease outbreaks and other threats with potentially risky government responses may vary significantly depending on local contexts and that the South Florida experience was a missed opportunity to test the strategy of trade-off framing.
\end{abstract}

Keywords Risk framing $\cdot$ Public engagement $\cdot$ Zika virus $\cdot$ Risk trade-offs

\section{Introduction}

More complex environmental threats to society often entail new risks from government responses, creating unique challenges for public policy-makers. Public officials confronting a vector-borne disease outbreak, for instance, must consider the additional risks of responses such as aerial spraying of pesticides to control the disease. As the world faces more complex environmental risks in general, policy-makers are confronted with these kinds of risk trade-offs more frequently: problems in which policy responses contain their own uncertain risks.

Leigh Raymond

1raymond@purdue.edu

1 Purdue University, 100 N. University St., West Lafayette, IN 47907-2098, USA 
In communicating about these complex risks, public officials can choose different "frames" that promote different conceptualizations of the issue (Chong \& Druckman, 2007). Different frames generate different public responses, so the framing of these competing risks is a vital question for any policy-maker. Yet the scholarly literature has paid limited attention to how public officials describe these risk trade-offs to the public-how do officials frame these related risks in explaining their policy responses to the public. This lack of scholarly attention is unfortunate because there are good reasons to think that frames highlighting these trade-offs could be better at increasing public support for government actions and at building public trust in policy choices responding to a crisis (see generally, Pralle \& Boscarino, 2011; Pralle, 2006; Roeser, 2012: p. 1035).

This paper expands our understanding of risk framing in settings with prominent risk trade-offs by analyzing how public officials framed potential risks during a high-profile disease crisis, the Zika virus outbreak in South Florida in 2016. We focus on the Zika outbreak because it was a recent and important situation with competing risks from the crisis itself (infection with Zika) and a leading government response (harm from aerial spraying of insecticides). The Zika case is also useful because novel disease threats are a growing problem that often feature similar framing dilemmas, as was evident, for example, in the larger controversy over policy responses to the COVID-19 pandemic in 2020. Other emerging environmental risks feature similar trade-offs, especially threats from anthropogenic climate change that have motivated policy responses ranging from global geoengineering to local infrastructure like sea walls that create their own risks (Groves et al., 2014; Huttunen \& Hildén, 2013). The Zika case is thus a useful example of a broader category of environmental threats with prominent risk trade-offs.

Prior work suggests that local officials could have framed competing risks in the Zika case in at least four different ways (Table 1): (1) maximizing a risk by stressing its certainty and severity as a rationale for action, (2) reassuring the public that a risk is minimal, (3) urging the need for "precautionary" action in the face of an uncertain risk, and (4) highlighting the trade-off between risks in choosing a particular policy response. Given this variety of potential framing strategies, we ask two specific research questions in this paper: (1) Which of these risk frames were most prominently used by policy actors to discuss the risk of the environmental threat (Zika), and why? (2) Which risk frames were most prominently used by policy actors to discuss the risk of the government response (aerial spraying of insecticides), and why?

Based on prior research, we formulate two primary hypotheses. First, we expect (H1) public officials to most frequently use the risk maximization frame to emphasize the seriousness of risks from Zika, much as occurred in government communication around other vector-borne diseases such as West Nile virus (WNV). Second, based on prior research documenting the advantages of trade-off framing for policies ranging from lawn pesticides

Table 1 Possible risks frames for case study

\begin{tabular}{ll}
\hline Framing strategy & Definition \\
\hline $\begin{array}{l}\text { Risk maximization } \\
\text { Reassurance about risk }\end{array}$ & $\begin{array}{l}\text { Highlights certain and serious nature of risk and need for response } \\
\text { Highlights that risk is minimal, only easy actions needed to reduce risk, if any. } \\
\text { Also emphasizes that actions to minimize the risk are effective }\end{array}$ \\
$\begin{array}{l}\text { Precaution about risk } \\
\text { Trade-off between risks }\end{array}$ & $\begin{array}{l}\text { Acknowledges risks on both sides by balancing them against one another and } \\
\text { justifies taking the action with the lower level of risk }\end{array}$ \\
\hline
\end{tabular}


to nuclear power to hydraulic fracturing (Kalaf-Hughes \& Kear, 2017; Pralle, 2006; Pralle \& Boscarino, 2011), we hypothesize (H2) public officials to most frequently use a trade-off frame to communicate about the risk of aerial spraying.

Using qualitative content analysis of local media coverage of the outbreak and interviews with individuals who helped shape the Zika response strategy in South Florida, we fail to support either hypothesis. Instead, we find that the most prominent frame for both risks was a reassurance frame describing the risks from Zika and from aerial spraying of pesticides as relatively minimal. Indeed, trade-off frames in public statements about aerial spraying were very uncommon, which we conclude was a potential missed opportunity for facilitating better public engagement about the crisis. The paper discusses possible explanations for these results, as well as the implications of these framing choices for public engagement around future disease outbreaks and other environmental risks featuring risky government responses.

\section{Background: the 2016 South Florida Zika outbreak}

The Zika virus is a vector-borne disease transmitted by the mosquito Aedes aegypti that can cause microcephaly in newborns as well as Guillain-Barré syndrome in adults. After re-emerging in South America in 2015, the virus came to the USA in July 2016, when the first locally transmitted cases were discovered in the Wynwood neighborhood in Miami, Florida. The number of locally infected people continued to increase through August and September as cases spread to South Miami and Miami Beach, as well as neighboring Palm Beach County. During this period, the U.S. Centers for Disease Control (CDC) issued a travel warning to pregnant women to avoid parts of the local transmission area (Likos et al., 2016).

Initial local government responses to the outbreak included efforts to reduce infected mosquito populations by eliminating standing water, and ground spraying of insecticides from backpacks and trucks (Florida Department of Health, 2016a). In most areas, these efforts were supplemented by aerial applications of naled, a pesticide targeting adult mosquitoes (Likos et al., 2016). (In addition to naled, the organic larvicide Bti was also aerially sprayed in areas with local transmissions.) Aerial spraying was conducted in Wynwood throughout August and in South Miami Beach between September 9 and September 24 (Fig. 1).

Some Miami-Dade residents protested the aerial spraying of naled. This opposition cited evidence of human health risks from naled at higher levels of exposure as well as toxicity to bees and other beneficial organisms (see generally, CDC, 2018; Hoang \& Rand, 2015a; Hoang \& Rand, 2015b; Silver et al., 2017; Virginia Department of Health, 2019) and the fact that the product was not approved for use in Europe. Opposition came to a head at an Emergency Workshop organized by the Miami Beach City Commission on September 7, where multiple members of the public expressed their fear that naled was toxic with effects "equal or worse than Zika" (Miami Beach City Commission Emergency Workshop, 2016). Although they may have represented a minority view in the state of Florida (Winneg et al., 2018), the protests gained substantial attention and some political support. Miami Beach Commissioner Michael Grieco, for example, declared that residents were "scared and angry" in stating his objection to spraying in Miami Beach (Miami Beach City Commission Emergency Workshop, 2016). 


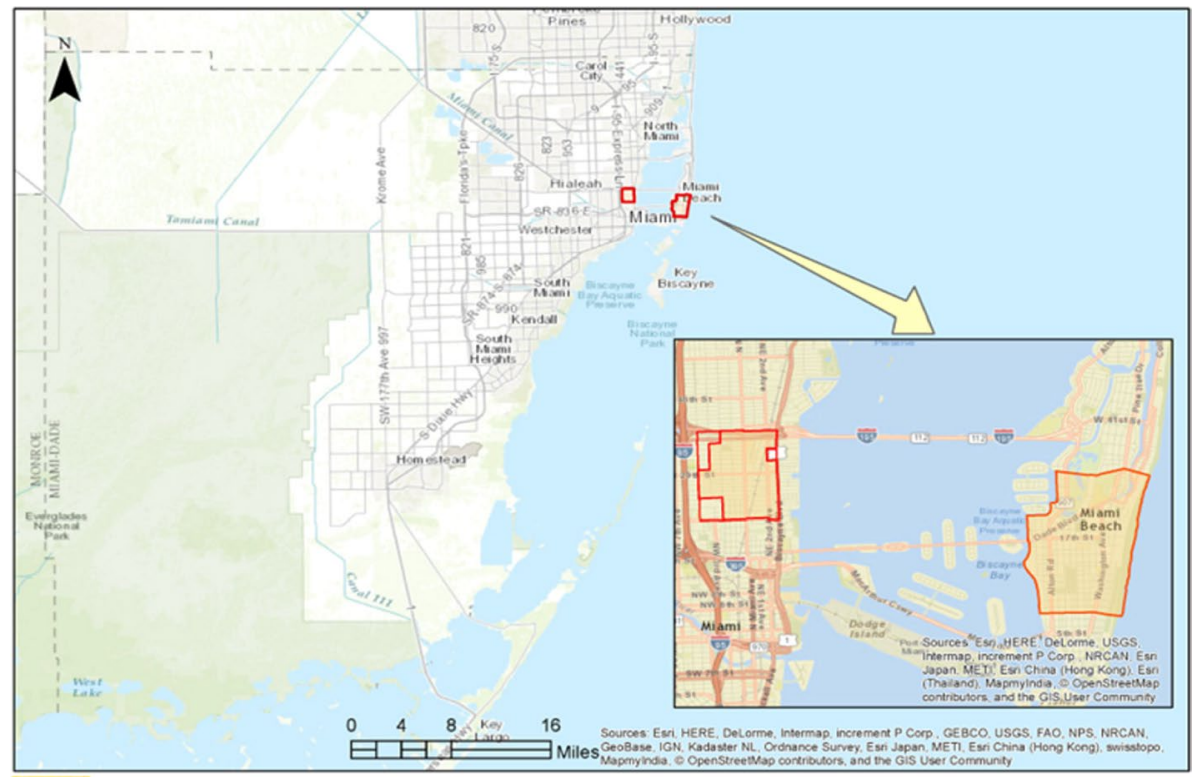

Areas of Active Local Zika Virus Transmission - August 22, 2016

Wynwood Area - NW 5th Avenue to the west, US 1 to the east, NW/NE 38th Street to the north and NW/NE 20th Street to the south

Miami Beach Area - 28th Street to the north, 8th Street to the south, Intercoastal water to the west and the Atlantic Ocean to the east

Fig. 1 Areas of active local transmission of Zika in South Florida. Source Florida Department of Health

In addition to these safety concerns, some local officials also questioned naled's effectiveness in killing Aedes aegypti. For example, the city of Palm Beach did not conduct aerial spraying of naled based on the Miami controversy and concerns about its ineffectiveness, opting to use an alternative pesticide sprayed from trucks and engaging in large public education campaigns (Zeidman, 2019). South Miami Mayor Philip Stoddard also publicly questioned the effectiveness of the aerial spraying strategy (Iannelli, 2016a).

The last round of aerial adulticide spraying occurred toward the end of August in Wynwood and stopped in South Miami Beach after September (Florida Department of Health, 2016a). Instead, adulticides and larvicides were applied on the ground from trucks (Florida Department of Health, 2016a; Miami-Dade Department of Mosquito Control n.d.). As spraying continued primarily from ground-level trucks, the number of Zika cases started to decline in late October and November. By December 7, Governor Scott declared Miami and South Beach free from local active transmissions for 45 consecutive days making Florida free from active Zika transmission (Florida Department of Health, 2016b).

\section{Prior findings on risk framing}

In this section, we discuss prior work on public risk framing, including research documenting the four risk framing strategies summarized in Table 1. We focus on research looking at disease risks in particular, but also consider other studies of risk framing as relevant. In this section, we articulate our contribution to the risk framing literature by noting the lack of 
empirical work on frames related to risk trade-offs, despite the growing relevance of such trade-offs in future environmental policy making.

\section{Framing, public risk perceptions and policy support}

Like many scholars studying frames, we follow Entman (1993: p. 52) in our understanding of framing as a way to: "select some aspects of a perceived reality and make them more salient...in such a way as to promote a particular problem definition, causal interpretation, moral evaluation, and/or treatment recommendation...." Thus, political actors engage in issue framing by promoting a different "conceptualization" of an issue to try to foster different attitudes toward specific policy responses (Chong \& Druckman, 2007). Famous examples include studies showing changes in public opinion toward hate speech and capital punishment when the issues are framed differently (Baumgartner et al., 2008; Nelson et al., 1997).

Researchers have identified framing as a key element of risk communication and policymaking (e.g., Allan et al., 2010; Lawlor \& Crow, 2018; Thorn, 2018). Research has explored framing strategies for multiple sources of risks, including diseases (e.g., Klemm et al. 2016; Sell et al., 2018), synthetic chemicals (Pralle, 2006; Raymond \& Olive, 2009), energy technologies (Pidgeon et al., 2008; Pralle and Bosarino 2011), climate change (Bilandzic et al., 2017; Nisbet \& Newman, 2015; Spence \& Pidgeon, 2010; Weathers and Kendall, 2016), geoengineering and carbon capture and storage (Raimi et al., 2019; Thomas et al., 2018), nanotechnology (Allan et al., 2010), and natural disasters (Lawlor \& Crow, 2018). In this respect, risk framing can be seen as a critical element of the larger issue of risk communication-how experts describe and explain different risks to different publics (Litfin, 1995; Nisbet \& Mooney, 2007).

Some work in this tradition focuses on how the media chooses risk frames, (e.g., Dan \& Raupp, 2018; Lawlor \& Crow, 2018), while others have looked specifically at the framing choices of policy advocates and decision-makers (e.g., Thorn, 2018; Tickner, 2002). Our study contributes to the latter body of work by focusing on the framing choices of public officials. Prior work specifically on risk framing has identified many types of frames (e.g., Dan \& Raupp, 2018). Among these many frames, the four we consider in our study (Table 1) all feature in prior studies of risk framing as discussed below. We note that despite the growing prominence of trade-offs in policies confronting newly emerging disease and climate change risks, relatively few studies have explicitly considered the prevalence of frames stressing those trade-offs directly, providing an important motivation for our work.

\section{Risk maximization frames}

An important thread in the literature on risk framing is the idea that "risk maximizing" frames are common for many types of risks, including natural disasters (Lawlor \& Crow, 2018), some climate change risks (Hart \& Feldman, 2014), and many public health threats (e.g., Klemm et al., 2016). Research in this tradition has identified the tendency of the media to frame risks in an "alarmist" manner to increase public attention and readership (Dan \& Raupp, 2018), although other work has focused on the reasons why decision-makers may adopt these risk maximizing frames.

In the context of health risks, studies of media framing have noted a high percentage of risk maximizing frames. A review of work on media framing of the H1N1 virus (or "Swine 
flu"), for example, found that "threat" and "severity" frames appeared frequently across multiple media sources (Klemm et al., 2016). A previous study of media framing of the 2016 Zika outbreak also found that "risk-elevating" messages were more common than "risk minimizing" messages, both nationally and in media coverage in areas affected by the outbreak (Sell et al., 2018).

Research on the framing choices by policy actors for disease outbreaks has found similar results, especially with respect to another vector-borne disease: West Nile Virus (WNV). Studies of multiple WNV outbreaks find that decision-makers emphasized disease risks in order to justify greater discretion for public responses to controlling the disease (McCormick \& Whitney, 2013; Scott, 2005; Tickner, 2002). Creating a "state of emergency" in this manner allows officials to circumvent normal governance regimes and extend their authoritative power to "intervene in ways that [are] considered heavy-handed and illegal by their critics," such as some forms of aerial spraying (McCormick \& Whitney, 2013, p. 270). Public officials also tend to focus on the "short-term knowable risks" associated with the disease, which are cognitively available and emotionally powerful, while "undervaluing" risks associated with pesticides as a public response, which may manifest in more subtle and long-term ways than the virus (Scott, 2005: p. 30; Tickner, 2002: p. 73).

This prior research, especially in the context of WNV outbreaks, suggests that the risk maximization frame will be the most common framing strategy for risks from Zika used by public officials during the 2016 outbreak. On the other hand, it suggests that risk maximization frames are unlikely to be used by public officials to describe risks from a government response such as the aerial spraying of pesticides.

\section{Reassurance frames}

Research has also documented how public officials sometimes focus on reassuring the public about uncertain risks, especially from new technologies, rather than inviting a discussion of risk trade-offs (McAvoy, 1998; O’Brien, 2000; Whiteside, 2006). Sell et al. (2018) found that risk minimization messages related to risks from Zika appeared with some frequency, although less commonly than risk maximizing messages. Observers of this pattern of framing are often critical of the approach, urging "greater public engagement in decision-making" especially in situations where there exist "expert-public disagreements about the acceptability of many technological risks, siting controversies, and declining public trust in policy-related science" (Petts, 2004: p. 116; Vegt, 2018: p. 1440). For this reason, we investigate the prevalence of reassurance frames for public officials about Zika and also about risks from aerial spraying.

\section{Precautionary frames}

Scholars have also found that precautionary framing is prevalent in official discussions of many environmental risks, especially related to health effects. Precautionary frames are less well defined than risk maximizing or reassurance frames, being caught up in debates over the exact meaning of the broadly interpreted idea of the Precautionary Principle (Pereira di Salvo \& Raymond, 2010; Sunstein, 2005; Whiteside, 2006). But these frames typically follow the maxim of "better safe than sorry" in terms of limiting a given risk, despite any uncertainties about the details of the risks in question.

Advocates have successfully used precautionary frames in a number of public health settings. Precautionary frames for health risks from stratospheric ozone depletion helped 
motivate a more aggressive international policy on the problem in the 1990s (Litfin, 1995), and similar frames have appeared in regulatory debates related to potentially toxic chemicals in the European Union (Eckley \& Selin, 2004), Canada (Pralle, 2006), and a number of U.S. states (Raymond \& Olive, 2009). In these cases, advocates successfully promoted frames stressing the need for governments to "err on the side of caution" in limiting uncertain risks from new chemicals or technologies. This type of precautionary frame could easily be applied to government actions around spraying pesticides or other chemicals to respond to a disease outbreak like Zika.

Alternatively, precautionary framing can also put responsibility on individuals to minimize a potential risk. Although this would be inconsistent with most interpretations of the Precautionary Principle, this focus on individuals reduces government responsibility without necessarily dismissing the need for some public concern. Such a frame could apply both to a new disease or other threat (such as a disease outbreak) or to government actions to address that threat. For example, in the Zika case a precautionary frame for the disease might stress individual responsibility to reduce personal risk of the disease by wearing insect repellent and avoiding areas with known cases of disease transmission, even when risks are still low. Or in terms of aerial spraying, a precautionary frame stressing individual responsibility might concentrate on personal actions to limit potential exposure by closing windows and staying indoors, given the potential health threat from spraying. Thus, we see precautionary framing as possible for both risks from Zika itself and from public mitigation actions like aerial spraying of insecticides.

\section{Trade-off frames}

Pralle and Boscarino (2011: p. 326) define trade-off framing as a strategy that suggests that sacrifices in one area are "not only justifiable but necessary" to reduce other risks. Because regulators themselves may disregard these kinds of risk-risk trade-offs (Lofstedt \& Schlag, 2017; Sunstein, 2002) and because political actors often prefer to minimize "the perceived costs" of a policy (Kalaf-Hughes \& Kear, 2017), trade-off frames are expected to be less common in many policy contexts. Nevertheless, trade-off frames have been used to build support for controversial policies and technologies.

Nuclear energy, for example, has gained public support from frames that acknowledge its risks but portray them as smaller than the competing risks of climate change (Pralle \& Boscarino, 2011; see also Bickerstaff et al., 2008). Other research has found that support for carbon capture and storage technology increases when framed in terms of trade-offs with the risk of reliability problems for renewable energy (Thomas et al., 2018). In other words, when supporters of a technology or policy face established public concerns, they may be better off acknowledging those concerns in arguing for the strategy as a smaller risk than the alternative. As Pralle (2006: p. 183) notes in a study of efforts to ban residential lawn chemicals, trade-off frames "can be powerful tools in policy debates" by giving people choices without denying their "everyday experiences."

More recent and emerging work on framing risks from responses to public health crises have recommended frames that acknowledge public concerns about trade-offs with regard to the risks of some policy responses. Emerging work on vaccinations and COVID-19, for example, has found that frames recognizing the potential risks of a vaccine and contrasting them with greater long-term risks of the disease are a more promising strategy for increasing acceptance of vaccinations among those resistant to the idea (Diamond, 2021). 
Other work argues for explicit recognition of risk trade-offs in communicating with the public in other contexts. Prior research has shown that more attention to local knowledge and concerns among diverse stakeholders improves decision-making and facilitates trust building with the public over risk management (Kinchy, 2012; McAvoy, 1998). Petts (2008: p. 821) also reminds readers that both "academic and policy circles" promote public engagement as an important tool for building "public trust in risk decisions and decisionmakers." Unlike reassurance framing that follows the logic of technocratic methods and deference to experts, trade-off framing does not isolate the public and ignore their "emotions and intuitions" (Roeser, 2012: p. 1035).

Surprisingly, there is little empirical scholarship on the prevalence of trade-off frames despite calls for alternative strategies for communicating about complex risk dilemmas. Few studies have explicitly included attention to trade-off frames in their analysis of possible risk framing strategies, even as they have grappled with environmental threats and potential responses that entailed important risks. Although prior work on vector-borne disease outbreaks has noted the trade-off of risks from disease exposure versus from aerial spraying of dangerous compounds (Allen, 2018; Their, 2001), this work has not typically studied the use of trade-off framing by public officials. Our work seeks to fill this gap by centering trade-off frames in our empirical analysis of public official's statements about the Zika outbreak in 2016.

In sum, all four of these frames are viable candidates for public messages related to the risks from Zika and aerial spraying. Based on this prior work, we formulate the following hypotheses regarding the framing strategy of public officials during the outbreak to describe risks from the disease itself, and also from the government response of aerial spraying of naled.

Given the prominence of risk maximization framing in other vector-borne disease outbreaks such as West Nile virus, we hypothesize:

H1 Risk maximization frames will be the most prominent framing strategy used by policy actors for the environmental risk of Zika.

Given the public protest and previous concern over the risks associated with aerial spraying and research suggesting the political utility of trade-off frames for actions with widely perceived risks, we hypothesize:

H2 Risk trade-off frames will be the most prominent framing strategy used for the risk of the government response of aerial spraying of pesticides.

\section{Methods}

As noted, the Zika outbreak in 2016 was a prominent example of an environmental risk that required officials to consider potential risk trade-offs, and thus a good case for studying risk trade-off framing. Yet previous research on government responses to Zika has not explicitly considered risk trade-off framing, and prior theory and research on trade-off framing have yet to explore the area of new disease threats. Thus, our case is an excellent opportunity to extend research on trade-off framing to an important threat like Zika as a representative of a larger body of risks with likely trade-offs from policy responses. 
We used qualitative content analysis to explore how risk-related information was framed by public officials in South Florida. Following prior research (Lawlor \& Crow, 2018), we rely on media coverage as a data source for the frames used to debate the Zika crisis. In order to focus on the framing strategies of public officials, however, we limit our analysis to statements attributed directly to public officials in these articles. Thus, our data are composed of statements attributed to public officials in media coverage of the Zika outbreak in three South Florida newspapers between July 1, 2016, and December 31, 2016, regarding different risks. This timeframe was selected because it covers the entire stretch of the initial outbreak, from the discovery of the first locally transmitted cases to the Governor's declaration of the area as free of locally transmitted cases in December 2016. We assembled our sample through online key word searches of The Miami Herald, the Miami New Times, and the South Florida Sun Sentinel, using the search terms "Zika AND Miami AND pesticides." All results were manually reviewed, and redundant and irrelevant articles removed, resulting in 134 newspaper articles to be reviewed for frames.

We selected local newspaper articles as our primary source of data because they provide the most comprehensive contemporaneous record of risk communication and framing by public officials over the course of the outbreak. Although prior research has noted media bias in reporting public messages about disease outbreaks such as the Zika case, we took several measures to increase confidence that the frames reported in the media were a good measure of public officials' actual use of different frames. First, we double-checked our media framing data with information from public meeting records and interviews with key actors involved in the Zika response. Second, we collected our framing data from newspapers with very different audiences and editorial biases. The Miami Herald is a major daily paper for the Miami-Dade area, and The Sun Sentinel is a competing daily that also serves South Florida from its base in Fort Lauderdale. The Miami New Times, by contrast, is an alternative weekly paper with an investigative reporting focus. All three papers are owned by different media companies and hold different editorial philosophies. Finally, research on media risk framing suggests a greater propensity toward alarmist, risk-elevating stories, meaning we need to be most cautious about a bias toward an over-count of risk maximization frames in our data compared to actual statements by public officials. This expected bias only strengthens the significance of our finding that this frame was used rarely by public officials. Therefore, we are confident that our analysis captures a reasonably accurate record of risk framing by public officials during the outbreak.

The unit of analysis for our coding was a statement, which we defined as a continuous section of text in which a single source discussed a specific risk. A statement was identified based on the elements it contained - a statement consists of a single source discussing a specific risk (e.g., Zika or naled), and at least one framing strategy. Thus, a statement could be as short as a sentence or as long as a paragraph, and different newspaper articles in our sample contained between 1 and 8 coded statements. Types of sources included (1) elected officials from city, county, state, or federal government, and (2) unelected officials from local, county, federal, and international agencies. We also coded whether the risk being described was from Zika or from aerial spraying. Finally, we coded frames as being a maximization, reassurance, precautionary, or trade-off frame based on our understanding of these frames from the prior research discussed above (see Appendix for specific coding rules). In our sample of 134 articles, we identified 174 risk frames by public officials. Out of these 174 risk frames, 104 discussed the risk of Zika and 70 the risk of aerial spraying of naled.

Coding was done manually using the Qualitative Content Analysis software QDA Miner Version 5. We verified and confirmed the relevance of our four risk frames as well as our 
criteria for distinguishing them on a pilot sample before coding the full sample of data. An inter-coder reliability check on 20 percent of the sample generated a Krippendorff's alpha score of 0.72 , indicating an acceptable level of inter-coder agreement (Krippendorff, 2004).

In addition to media reporting, we also looked at public records regarding decision making during the crisis and interviewed individuals with first-hand knowledge about the outbreak response. These data, which were not formally coded, helped check for any bias in the framing patterns we observed in our media data, and offered insights on how participants thought about the risk framing issue and explained the public framing choices they observed. We identified interview subjects by reviewing our media sample for prominent actors in the Zika response effort, and by asking interviewees for other important individuals in the process. Our eight interview subjects included local mayors, federal, state, and county agency officials, academics, and private contractors. We conducted 30-60 min confidential, semi-structured phone interviews with these individuals, with specific comments approved for attribution by each subject consistent with the IRB protocol for the research. All interviews were recorded and then transcribed.

\section{Results}

We present our results in terms of each of our primary hypotheses regarding the most common frames for each risk: Zika and aerial spraying.

\section{Zika framing}

Table 2 summarizes the results of our content analysis for Zika frames, which do not support our hypothesis that risk maximization frames would be the most prominent framing strategy for the disease. In fact, risk maximization frames were used only 3 times for the disease, making them only $2.9 \%$ of all Zika frames in our sample.

Instead, the most common frame for Zika was a risk reassurance frame, which constituted 68 out of the 104 (65.4\%) Zika frames offered by public officials in our sample. Precautionary frames were a distant second $(29.8 \%)$ while trade-off frames were even more uncommon (1.9\%). Thus, the maximization frame that was most commonly used for other

Table 2 Number of Zika risk frames by source/actor

\begin{tabular}{|c|c|c|c|c|c|}
\hline & Maximization & Reassurance & Precaution & trade-off & Total \\
\hline \multicolumn{6}{|l|}{ Elected officials } \\
\hline City & & 6 & 2 & & 8 \\
\hline County & & 13 & 2 & & 15 \\
\hline State & & 8 & 2 & & 10 \\
\hline Federal & & 2 & 1 & 1 & 4 \\
\hline \multicolumn{6}{|l|}{ Agency officials } \\
\hline National agency & 3 & 16 & 16 & 1 & 36 \\
\hline County/city agency & & 17 & 3 & & 20 \\
\hline State agency & & 6 & 1 & & 7 \\
\hline International agency & & & 4 & & 4 \\
\hline Total & $3(2.9 \%)$ & $68(65.4 \%)$ & $31(29.8 \%)$ & $2(1.9 \%)$ & 104 \\
\hline
\end{tabular}


disease outbreaks, such as WNV, was one of the least commonly used frames for the Zika outbreak in 2016.

Table 2 shows the breakdown of these frames by specific sources. The most common sources for Zika frames were officials from national agencies, such as the Centers for Disease Control, and county/city agency representatives, such as local public health or vector control agencies. Local officials mostly used reassurance frames, for example assuring residents that "they have been actively spraying pesticides, checking drains and dumping standing water that can breed mosquitoes" (Herrera, 2016: p. 4). It is especially noteworthy that local officials never used a risk maximization frame in our sample, despite the precedent in other studies of local officials maximizing disease risks to justify greater freedom for their actions to control the disease threat.

National representatives, by contrast, frequently combined reassurance frames with precautionary ones, making precautionary frames relatively common in our sample as well. These precautionary frames, however, typically emphasized individual actions to limit the risk of exposure to Zika-carrying mosquitoes, such as warning pregnant women to stay away from areas with any active transmission (Ordoñez, 2016).

There is some evidence that concerns about tourism are part of why reassurance framing was the most common for Zika risks. Fairly early in the outbreak, journalists reported that despite aggressive measures employed to combat the outbreak, local politicians "rushed to reassure tourists that it's still safe to visit the state" (The Associated Press, 2016). Miami Mayor Regalado, for example, tried to "assuage fears over the virus" (Frías, 2016) sending a message of hope and security when addressing the effects of Zika on local businesses in Wynwood-a Miami neighborhood that heavily depends on tourism (Harris, 2016). Mayor Regalado tried to reverse "the chilling effect he said came along with the Centers for Disease Control's travel advisory warning pregnant women to avoid the area" (Harris, 2016). Governor Scott also added that "Tourism is a driving force of Florida's economy and this industry has the full support of our state in the fight against the Zika virus" (Flechas \& Chang, 2016a). Interviews with local officials indicated that tourism in South Florida was substantially affected by the outbreak (Zeidman, 2019), especially in South Beach (Vasquez, 2018). These data all support the potential importance of managing impacts on tourism in choosing a reassurance frame regarding Zika risks in this case.

In addition, some interviews suggest that officials may have felt it was important not to create panic, even as they recognized the seriousness of the Zika risk (McAllister, 2018; Zeidman, 2019). The majority of our interviewees recalled that agencies at all levels agreed that Zika was a great concern, especially for women of reproductive age. For example, former Mayor of South Miami, Philip Stoddard, recalled that the CDC and the Governor's office stressed the magnitude of the threat posed by Zika and that the CDC acknowledged "the prenatal risks of Zika were so great that any health or environmental risks from chemical control measures were insignificant by comparison" (Stoddard, 2018). Here is another important motivation for reassurance framing for the risk of Zika in particular.

\section{Aerial spraying}

Contrary to our second hypothesis, a risk trade-off frame was not the most prominent framing strategy for the policy of aerial spraying. There were a few examples of this frame in our sample, such as when Miami-Dade County Mayor Gimenez emphasized that he did not want to use aerial spraying of naled, but that it was necessary to reduce the number of mosquitoes potentially carrying Zika (Flechas \& Hanks, 2016). But this communication 
strategy remained quite uncommon, representing only $5.7 \%$ of the frames used with this risk (Table 3).

Instead, risk reassurance frames also dominated the discussion of aerial spraying of naled, making up $85.7 \%$ of all frames for that issue (Table 3). Typical uses of this frame emphasized that naled can be used in mosquito control "without posing a risk to people," (Viglucci, 2016) and that spraying "had been found to consistently kill more than $90 \%$ of Aedes aegypti in traps" (Kopp, 2016). Of course, as noted earlier in the paper, other research has suggested higher risks from naled exposure, or at least reason to be more concerned about the compound's impacts on other beneficial insects as well as potentially on people (Hoang \& Rand, 2015a; Silver et al., 2017).

Local and county officials often referenced federal messages to reassure local populations, stating that naled was "registered for use by both the EPA and [Florida Department of Agricultural and Consumer Services]" (Iannelli, 2016b). Politicians, such as MiamiDade Mayor Gimenez, also used a similar message to reassure the public that "air spraying has been a part of the mosquito control program for years" (Torres, 2016). The minutes of the Miami Beach public workshop on the Zika crisis confirms the use of a reassurance frame for aerial spraying by a wide range of officials, with a typical statement being: "aerial spraying using naled, in combination with larvicide treatment on the ground, is the safe thing to do at this time, and it is necessary to reduce the mosquito population in Miami Beach" (Miami Beach City Commission Emergency Workshop, 2016).

Precautionary framing appeared much less frequently for aerial spraying $(8.6 \%$ of all frames). Although Miami Beach Mayor Philip Levine said that he wanted "to know more about potential effects the spraying may have on residents" in response to the public protests in his city (Flechas \& Chang, 2016b, 4), most uses of this frame stressed individual precautions such as staying indoors with "windows shut and air conditioning off during spraying" (Viglucci, 2016: p. 4) rather than government actions. This is notable in that nearly all uses of precautionary framing for both Zika and aerial spraying in this case focused on individual actions rather than the more typical understanding of the Precautionary Principle requiring government or corporate caution toward uncertain risks. In addition, federal agencies did not stress precautionary frames related to limiting exposure to aerial spraying, offering those frames only four times in our dataset compared to 30 statements using the reassurance frame. This is a notable contrast from how they talked about

Table 3 Number of aerial spraying risk frames by source/actor

\begin{tabular}{|c|c|c|c|c|c|}
\hline & Maximization & Reassurance & Precaution & Trade-off & Total \\
\hline \multicolumn{6}{|l|}{ Elected officials } \\
\hline City & & 2 & 2 & 2 & 6 \\
\hline County & & 7 & & 1 & 8 \\
\hline State & & & & & 0 \\
\hline Federal & & & & & 0 \\
\hline \multicolumn{6}{|l|}{ Agency officials } \\
\hline National agency & & 30 & 4 & 1 & 35 \\
\hline County/city agency & & 20 & & & 20 \\
\hline State agency & & & & & 0 \\
\hline International agency & & 1 & & & 1 \\
\hline Total & $0(0 \%)$ & $60(85.7 \%)$ & $6(8.6 \%)$ & $4(5.7 \%)$ & 70 \\
\hline
\end{tabular}


risks from Zika, where they used both reassurance frames and precautionary messages at the same frequency.

Our interviews suggest the prevalence of reassurance framing for aerial spraying was grounded in a genuine belief among officials who chose to use naled that the product was low risk when following the label directions. Although public officials were aware of the public controversy over perceived risks from naled, some noted they felt these fears were exaggerated (McAllister, 2018; Vasquez, 2018) or that the public often based their views on incorrect information. The genuine belief that naled is safe and perhaps the only available option that works combined with concerns about tourism losses are the most likely reasons for the prevalence of reassurance framing we can identify, even though as noted in Part 2 some municipalities chose not to conduct aerial spraying of naled based on the Miami controversy.

\section{Discussion and implications}

Data on the statements of public officials related to the 2016 Zika virus outbreak in South Florida do not support either of our primary hypotheses: We did not find that public officials used risk maximization frames for the risks of Zika itself $(\mathrm{H} 1)$, or that they used risk trade-off frames for risks related to aerial spraying of the pesticide naled (H2). Contrary to our expectations, we found that public officials in South Florida relied primarily on a reassurance frame in talking about both risks from the Zika virus and possible risks from aerial spraying to help reduce the threat of the virus. Unlike studies of previous vectorborne disease outbreaks finding governments used a risk maximization frame to expand the range of acceptable policy responses, in the Zika case this type of messaging was rare. Worried about tourism and hoping to reduce public panic, officials framed the disease risk in ways that minimized the threat and highlighted efforts being taken to manage it. In terms of risks from aerial spraying of pesticides, the message was focused on assuring the public that there were no serious risks from aerial spraying, despite a vocal public protest based on perceived risks to public health and the environment. Here the framing strategy seems to have been based on a sense that these public fears were overblown and that spraying as conducted was indeed a practice with minimal risks when naled is applied according to label instructions.

These findings make several contributions to our understanding of risk framing in the context of disease threats and situations with potential risk trade-offs. First, they show that in the case of disease outbreaks, messages emphasizing the seriousness of the disease threat are not always the predominant form of risk framing. Although this was the pattern in several municipal responses to West Nile virus, a similar vector-borne disease, it was not seen in the South Florida case. Our research suggests this is due to a desire to avoid panic among citizens along with concerns about economic threats to tourism, but there are other possible reasons for the alternative risk framing strategy that prevailed in our Zika case. One such possibility is that different types of risks motivate different framing responses (see Lawlor \& Crow, 2018), and the especially "dreadful" nature of the risk from the Zika virus - birth deformities in newborn babies-may have spurred a different framing response. Regardless, the prevalence of these different strategies to communicate about disease risks across these two outbreaks suggests there is still wide variation in how officials communicate with the public about these critical disease risks and that the factors influencing those risk framing choices remain complex and not well understood. 
Second, the preference for reassurance framing over trade-off framing for risks from aerial spraying is also an important finding. The relative lack of even precautionary framing about aerial spraying in our dataset is noteworthy-officials mostly dismissed public concerns about spraying. Even federal officials, who combined reassurance and precautionary frames regarding the risks from Zika itself, stuck almost entirely to reassurance framing for aerial spraying. This framing pattern suggests a failure to accept or acknowledge the public's risk concerns as well as potential economic pressure to dismiss these concerns, both reasons cited as common causes of a reassurance strategies about risks from new technologies (e.g., O’Brien, 2000; Tickner, 2002). Here again is an opportunity for more research on the process by which public officials choose frames not only for a particular environmental threat, like Zika, but just as importantly for risks from the potential government response to that threat.

In this respect, we posit that the South Florida experience was a missed opportunity to use trade-off framing for risk communication related to disease outbreaks, given the body of research suggesting that talking directly about trade-offs can improve public acceptance of different risks as well as public engagement with the policy process (Pralle, 2006; Roeser, 2012), as discussed in the "Prior findings on risk framing" section above. Even if the public sometimes has trouble understanding certain types of risks (e.g., Sunstein, 2002), research still suggests that governments are better off acknowledging those worries publicly as they explain their preferred response. It is notable here that efforts to change public attitudes toward more recent disease responses, such as vaccinations for COVID-19, seem to be more effective when recognizing the risk trade-offs and stressing the larger size of the risks of the disease itself.

Based on our findings, we conclude it would be helpful for scholars to directly study whether trade-off frames are more effective at building public support for potentially risky responses to disease outbreaks like Zika, as well as other types of complex risks such as climate change adaptation or geoengineering. We think that comparing risk framing strategies by governments from the more recent and more widespread COVID-19 threat with those in the Zika case and other disease risks would be especially fruitful. Future research should also focus not only on how governments are framing these risks, but also on testing the effect of trade-off frames on the public. This work could draw on both survey research and experimental treatments of different frames as well as focus group strategies for understanding different framing effects (for similar research designs, see Andrews et al. 2017; Delshad et al., 2010).

\section{Conclusion}

Based on the content analysis of newspaper articles and interviews with some of the key actors during the 2016 Zika outbreak in South Florida, we found that the most prominent frame for both risks - those associated with Zika and the aerial spraying of naled-was a reassurance frame stressing the risk is minimal and being effectively controlled. Contrary to our expectation that officials would maximize the risk of Zika, they largely avoided such frames. In addition, officials did not frame risks from aerially spraying pesticides by using a trade-off frame, as we expected, but instead reassured the public that naled posed no risk to human and environmental health when correctly applied. Our research suggests that public officials may have relied on the reassurance frame for several reasons, including a desire to limit public panic about the threat of Zika, a dismissal of public concerns about 
aerial spraying as uninformed, and possible economic incentives to limit the perceived severity of the outbreak.

Rather than reassurance messages, we propose that trade-off framing could have been a more effective and more ethical communication strategy in the context of established disagreement about risks of aerial spraying. Whatever the beliefs of officials about the validity of the public perceptions of the risk of aerial spraying in particular, they might have benefited from acknowledging those risks even in promoting their preferred response to the crisis. More generally, the South Florida case shows how public officials continue to struggle with different framing strategies for complex environmental risks such as those related to a new disease outbreak and that there is no clear pattern of communication strategies for risks across cases. We see that although in some previous cases (such as WNV), public officials have chosen to maximize risks, here they largely took an opposite approach. Therefore, it is important to continue research on the reasons why governments choose different risk frames for similar types of risks in different settings, as well as a different line of research on the effects of different framing strategies on the public related to a range of such risk trade-offs in the future, as the world faces more environmental threats accompanied by their own potentially risky government responses.

\section{Appendix}

\section{Risks and risk frames definitions}

The table contains detailed definitions of risks and risk framing strategies that were used to code the sample of 134 local newspaper articles. These definitions guided coders in making decisions about coding articles and identifying risk frames in the statements made by public official sources (Table 4).

Table 4 Coding rules for risk frames

\section{Risks}

Zika

Aerial spraying of pesticides

Risk framing strategies

Risk maximization

Risk reassurance

Risk trade-off

Risk precaution
Used when the source refers to Zika virus as a risk

Used when the source refers to aerial spraying naled as a risk

A risk maximization frame includes statements that graphically or dramatically describes the worst potential consequences of a risk in a way that evokes negative emotions such as fear and concern.

A reassurance frame includes statements that range from encouraging calm and asserting that the risk exists but is not serious to outright denials of the risk. Reassurance can also include information on how existing actions to minimize the risk (e.g., spraying pesticides) are or will be effective.

A trade-off frame includes statements that balance risks against one another, usually making a recommendation for choosing between the two. For example, a source can acknowledge that aerial spraying of naled may pose some risks to human health but states that those risks are minor in comparison to the seriousness of Zika (and vice versa).

A precaution frame includes statements that urge an action to limit potential harm from an unknown risk, or to avoid being surprised by a risk. It involves an element of the unknown-the risks are uncertain, but it is recommended that an action be taken to avoid possible harm. Precaution can also be used to urge a measured, careful approach to decision-making. 
Acknowledgements Funding for this research was provided by Purdue University's "Big Ideas Challenge." The authors thank Dr. Catherine Hill and other members of the interdisciplinary Big Ideas team for their feedback on earlier drafts of the paper, as well as three anonymous reviewers and the editors for Policy Sciences.

\section{References}

Allan, S., Anderson, A., \& Petersen, A. (2010). Framing risk: Nanotechnologies in the news. Journal of Risk Research, 13(1), 29-44. https://doi.org/10.1080/13669870903135847

Allen, M. P. (2018). Chronicling the risk and risk communication by governmental officials during the Zika threat. Risk Analysis, 38(12), 2507-2513.

Andrews, A. C., Clawson, R. A., Gramig, B. M., \& Raymond, L. (2017). Finding the right value: Framing effects on domain experts. Political Psychology, 38(2), 261-278. https://doi.org/10.1111/pops.12339

Associated Press. (2016). 4 Zika cases in Broward, Miami-Dade likely came from Florida mosquitoes, Gov. Scott Says. Sun Sentinel. Retrieved September 6, 2019 from https://www.sun-sentinel.com/health/sflap-four-zika-cases-florida-20160729-story.html

Baumgartner, F. R., De Boef, S., \& Boydstun, A. (2008). The decline of the death penalty and the discovery of innocence. Cambridge University Press.

Bickerstaff, K., Lorenzoni, I., Pidgeon, N. F., Poortinga, W., \& Simmons, P. (2008). Reframing nuclear power in the UK energy debate: Nuclear power, climate change mitigation and radioactive waste. $P u b$ lic Understanding of Science, 17(2), 145-169. https://doi.org/10.1177/0963662506066719

Bilandzic, H., Kalch, A., \& Soentgen, J. (2017). Effects of Goal Framing and Emotions on Perceived Threat and Willingness to Sacrifice for Climate Change. Science Communication, 39(4), 466-491. https://doi. org/10.1177/1075547017718553

Center for Disease Control and Prevention, National Center for Emerging and Zoonotic Infectious Diseases, Division of Vector-borne Diseases. (2018). Information on aerial spraying. Retrieved September 7, 2019, from https://www.cdc.gov/westnile/vectorcontrol/aerial-spraying.htm

Chong, D., \& Druckman, J. N. (2007). Framing theory. Annual Review of Political Science, 10, $103-126$.

Dan, V., \& Raupp, J. (2018). A systematic review of frames in news reporting of health risks: Characteristics, construct consistency vs. name diversity, and the relationship of frames to framing functions. Health, Risk \& Society, 20(5-6), 203-226. https://doi.org/10.1080/13698575.2018.1522422

Delshad, A. B., Raymond, L., Sawicki, V., \& Wegener, D. T. (2010). Public attitudes toward political and technological options for biofuels. Energy Policy, 38(2010), 3414-3425.

Diamond, D. (2021). 'We want to be educated, not indoctrinated,' say Trump voters wary of coronavirus vaccination. The Washington Post. Retrieved March 15, 2021, from https://www.washingtonpost.com/ health/2021/03/15/vaccine-hesitant-republicans-focus-group/

Eckley, N., \& Selin, H. (2004). All talk, little action: Precaution and european chemicals regulation. Journal of European Public Policy, 11(1), 78-105.

Entman, R. M. (1993). Framing: Towards clarification of a fractured paradigm. Journal of Communication, 43(4), 51-58.

Flechas, J., Daniel, D. (2016b). Aerial spraying for Zika in Miami Beach begins Thursday. Miami Herald. Retrieved September 6, 2016, from https://www.miamiherald.com/news/health-care/article100155007. html

Flechas, J., \& Chang, D. (2016a). Zika now spreading in Miami Beach, sources say. Miami Herald. Retrieved August 18, 2016, from https://www.miamiherald.com/news/health-care/article96420487. html

Flechas, J., \& Hanks, D. (2016). Zika zone triples in Miami Beach after more cases found. Miami Herald. Retrieved September 6, 2019, from https://www.miamiherald.com/news/nation-world/national/artic le102462592.html

Florida Department of Health. (2016b). Department of health daily Zika update. Retrieved September 7 , 2019, from http://www.floridahealth.gov/newsroom/2016/12/120916-zika-update.html

Florida Department of Health. (2016a). Department of health daily Zika update. Retrieved September 7, 2019, from http://www.floridahealth.gov/newsroom/2016/12/121416-zika-update.html

Frías, C. (2016). Zika fears force several outdoor party cancelations in Wynwood. Miami Herald. Retrieved September 6, 2019 from https:/www.miamiherald.com/entertainment/restaurants/artic le93776042.html 
Groves, D. G., Fischbach, J. R., Knopman, D., Johnson, D. R., \& Giglio, K. (2014). Strengthening coastal planning how coastal regions could benefit from louisiana's planning and analysis framework. RAND Corporation.

Harris, A. (2016). Despite Zika scare, Wynwood art walks draws a crowd. Miami Herald. Retrieved May 24, 2020, from https://www.miamiherald.com/news/health-care/article95607322.html

Hart, P. S., \& Feldman, L. (2014). Threat without efficacy? Climate change on U.S. network news. Science Communication, 36(3), 325-351. https://doi.org/10.1177/1075547013520239

Herrera, C. (2016). Miami's tourism industry faces its newest foe: Zika in Wynwood. Miami Herald. Retrieved September 6, 2019, from https://www.miamiherald.com/news/business/tourism-cruises/ article93064732.html

Hoang, T. C., \& Rand, G. M. (2015a). Acute toxicity and risk assessment of permethrin, naled, and dichlorvos to larval butterflies via ingestion of contaminated foliage. Chemosphere, 120, 714-721.

Hoang, T. C., \& Rand, G. M. (2015b). Mosquito control insecticides: A probabilistic ecological risk assessment on drift exposures of naled, dichlorvos (naled metabolite) and permethrin to adult butterflies. Science of the Total Environment, 502, 252-265.

Huttunen, S., \& Hildén, M. (2013). Framing the controversial: Geoengineering in academic literature. Science Communication, 36(1), 3-29.

Iannelli, J. (2016b). Pesticide sprayed over Wynwood is banned in Europe, may also harm fetuses. Miami New Times. Retrieved September 6, 2019, from https:/www.miaminewtimes.com/news/ pesticide-sprayed-over-wynwood-is-banned-in-europe-may-also-harm-fetuses-8671169

Iannelli, J. (2016a). Naled not working in Miami Beach, FIU analysis shows. Miami New Times. Retrieved September 6, 2019, from https://www.miaminewtimes.com/news/naled-not-working-inmiami-beach-fiu-analysis-shows-8796398

Kalaf-Hughes, N., \& Kear, A. R. (2017). Framed for compromise? The role of bill framing in state legislative behavior on natural gas policy. Policy Studies Journal, 46(3), 598-628.

Kinchy, A. (2012). Seeds, science, and struggle: The global politics of transgenic crops. The MIT Press.

Klemm, C., Das, E., \& Hartmann, T. (2016). Swine flu and hype: A systematic review of media dramatization of the H1N1 influenza pandemic. Journal of Risk Research, 19(1), 1-20. https://doi.org/10. 1080/13669877.2014.923029

Kopp, E. (2016). Fighting Zika: Is aerial spraying effective?. Miami Herald. Retrieved September 6, 2019, from http://www.miamiherald.com/news/health-care/article98150357.html

Krippendorff, K. (2004). Reliability in content analysis: Some common misconceptions and recommendations. Human Communication Research, 30(3), 411-433.

Lawlor, A., \& Crow, D. (2018). Risk-based policy narratives. Policy Studies Journal, 46(4), 843-867.

Likos, A., et al. (2016). Local mosquito-borne transmission of Zika virus - Miami-Dade and Broward counties, Florida, June-August 2016. MMWR. Morbidity and Mortality Weekly Report, 65(38), 1032-1038.

Litfin, K. T. (1995). Framing science: Precautionary discourse and the ozone treaties. Millenium: Journal of International Studies, 24(2), 251-277.

Lofstedt, R., \& Schlag, A. (2017). Risk-risk tradeoffs: What should we do in Europe? Journal of Risk Research, 20(8), 963-983.

McAllister, J. (2018). Personal phone interview, October 31.

McAvoy, G. E. (1998). Partisan probing and democratic decisionmaking: Rethinking the NIMBY Syndrome. Policy Studies Journal, 26(2), 274-292.

McCormick, S., \& Whitney, K. (2013). The making of public health emergencies: West Nile virus in New York City. Sociology of Health \& Illness, 35(2), 268-279.

Miami-Dade Department of Mosquito Control. N.d. Mosquito season statistical highlights. Copy on file with the author.

Nelson, T. E., Clawson, R. A., \& Oxley, Z. M. (1997). Media framing of a civil liberties conflict and its effect on tolerance. American Political Science Review, 91(3), 567-583.

Nisbet, M. C., \& Mooney, C. (2007). Framing science. Science, 316(5821), 56. https://doi.org/10.1126/ science. 1142030

Nisbet, M. C., \& Newman, T. P. (2015). Framing, the media, and environmental communication. In H. Anders \& J. R. Cox (Eds.), The routledge handbook of environment and communication (pp. 325-338). Routledge.

O'Brien, M. (2000). Making better environmental decisions: An alternative to risk assessment. MIT Press.

Ordoñez, F. (2016). Millenials confront dating and sex in the time of Zika. Miami Herald. Retrieved May 28, 2020, from https://www.miamiherald.com/news/health-care/article95330072.html 
Pereira Di Salvo, C. J., \& Raymond, L. (2010). Defining the precautionary principle: An empirical analysis of elite discourse. Environmental Politics, 19(1), 86-106.

Petts, J. (2004). Barriers to participation and deliberation in risk decisions: Evidence from waste management. Journal of Risk Research, 7(2), 115-133.

Petts, J. (2008). Public engagement to build trust: False hopes? Journal of Risk Research, 11(6), $821-835$.

Pidgeon, N. F., Lorenzoni, I., \& Poortinga, W. (2008). Climate change or nuclear power-No thanks! A quantitative study of public perceptions and risk framing in Britain. Global Environmental Change, $18(1), 69-85$.

Pralle, S. (2006). The "mouse that roared": Agenda setting in Canadian pesticides politics. Policy Studies Journal, 34(2), 171-194.

Pralle, S., \& Boscarino, J. (2011). Framing trade-offs: The politics of nuclear power and wind energy in the age of global climate change. Review of Policy Research, 28(4), 323-346.

Raimi, K. T., Maki, A., Dana, D., \& Vandenbergh, M. P. (2019). Framing of geoengineering affects support for climate change mitigation. Environmental Communication, 13(3), 300-319. https://doi.org/ $10.1080 / 17524032.2019 .1575258$

Raymond, L., \& Olive, A. (2009). Ideas, discourse, and rhetoric in political choice. Polity, 41(2), $189-210$.

Roeser, S. (2012). Risk communication, public engagement, and climate change: A role for emotions. Risk Analysis, 32(6), 1033-1040.

Scott, D. N. (2005). When precaution points two ways: Confronting "West Nile Fever." Canadian Journal of Law \& Society/la Revue Canadienne Droit Et Société, 20(2), 2765.

Sell, T. K., et al. (2018). Frequency of risk-related news media messages in 2016 coverage of Zika virus. Risk Analysis, 38, 2514-2524. https://doi.org/10.1111/risa.12961

Silver, M. K., Shao, J., Zhu, B., Chen, M., Xia, Y., Kaciroti, N., Lozoff, B., \& Meeker, J. D. (2017). Prenatal naled and chlorpyrifos exposure is associated with deficits in infant motor function in a cohort of Chinese infants. Environment International, 106, 248-256. https://doi.org/10.1016/j.envint.2017.05.015

Spence, A., \& Pidgeon, N. (2010). Framing and communicating climate change: The effects of distance and outcome frame manipulations. Global Environmental Change, 20, 656-667.

Stoddard, P. (2018). Personal Phone Interview, July 31.

Sunstein, C. R. (2002). Risk and reason. Cambridge University Press.

Sunstein, C. R. (2005). Laws of fear: Beyond the precautionary principle. Cambridge University Press.

Their, A. (2001). Balancing the risks: Vector control and pesticide use in response to emerging illness. Journal of Urban Health, 78(2), 372-381.

Thomas, G., Pidgeon, N., \& Roberts, E. (2018). Ambivalence, naturalness and normality in public perceptions of carbon capture and storage in biomass, fossil energy, and industrial applications in the United Kingdom. Energy Research \& Social Science, 46, 1-9. https://doi.org/10.1016/j.erss.2018.06.007

Thorn, A. (2018). Issue definition and conflict expansion: The role of risk to human health as an issue definition strategy in an environmental conflict. Policy Sciences, 51(1), 59-76. https://doi.org/10. 1007/s11077-018-9312-X

Tickner, J. A. (2002). The precautionary principle and public health trade-offs: Case study of West Nile Virus. The ANNALS of the American Academy of Political and Social Science, 584(1), 69-79.

Torres, A. (2016). Mayor runs into protestors angry over pesticides to fight Zika. Miami Herald. https:// www.local10.com/health/zika-virus/mayor-runs-into-protesters-angry-over-pesticides-to-fight-zika

van der Vegt, R. G. (2018). A literature review on the relationship between risk governance and public engagement in relation to complex environmental issues. Journal of Risk Research, 21(11), 1-18.

Vasquez, C. (2018). Personal phone interview, November 2.

Viglucci, A. (2016). Is insecticide sprayed to fight Zika a risk for people and wildlife? Miami Herald. Retrieved September 6, 2019, from https://www.miamiherald.com/news/health-care/article951 58007.html

Virginia Department of Health. Frequently Asked Questions about Dibrom (Naled). Retrieved September 6, 2019, from http://www.vdh.virginia.gov/environmental-epidemiology/fact-sheets-for-publichealth/frequently-asked-questions-about-dibrom-naled/

Weathers, M. R., \& Kendall, B. E. (2016). Developments in the framing of climate change as a public health issue in US newspapers. Environmental Communication, 10(5), 593-611. https://doi.org/10. 1080/17524032.2015.1050436

Whiteside, K. H. (2006). Precautionary politics: Principle and practice in confronting environmental risk. MIT Press. 
Winneg, K., et al. (2018). Differences between florida and the rest of the united states in response to local transmission of the Zika virus: Implications for future communication campaigns. Risk Analysis, 38(12), 2546-2560.

Miami Beach city commission emergency workshop. (2016). City of Miami Beach. Copy on file with the author.

Zeidman, M. (2019). Personal phone interview, March 11.

Publisher's Note Springer Nature remains neutral with regard to jurisdictional claims in published maps and institutional affiliations. 